\title{
Editorial Note for Special Issue on the Evaluation of Digital Cultural Resources-January 2019
}

Digital technologies have a significant impact on all areas of operation of cultural heritage organisations, from documenting, interpreting, and exhibiting the collections to communicating and interacting with diverse audience groups. As the cultural heritage sector is gaining substantial experience in communicating collections information in multiple digital forms-whether an online catalogue, virtual exhibition, mobile app, museum interactive, or social media exchange-the focus of both practitioners and researchers working in this area has started shifting to user engagement, which increasingly affects cultural encounters and shapes users' perception of cultural organisations. Cultural and educational institutions around the world are heavily investing into digitisation and the development and use of various digital tools to make their collections accessible both online and onsite. Yet, we still know relatively little about who uses these digital collections and applications, how they interact with the associated data, how they value these cultural services, and what the impacts of these digital resources are, both on the users and the organisations themselves.

This special issue seeks to address this gap by bringing together specialists from a range of disciplines, practices, and sectors (such as digital heritage, museology, information studies, human-computer interaction, and digital humanities) to discuss the latest developments on evaluating the use of digital cultural resources. It looks at the latest research and critical thinking in the evaluation of digital cultural heritage, covering a wide range of applications from mobile apps and serious games to online catalogues and textual digital editions; engaging with cultural heritage and audiences of diverse type and size in an international context; and integrating various theoretical approaches and methodological tools. Apart from innovative research, the issue includes also critical reflections about the potential and shortcomings of evaluation research in digital cultural heritage and its impact upon professional practices, policies, and strategies of not only cultural organizations but also research, governing, and funding bodies.

The idea for this special issue arose from the activities of the Scottish Network on Digital Cultural Resources Evaluation (ScotDigiCH), funded by The Royal Society of Edinburgh in 2015-2016, and particularly from the discussions and papers presented at the International Symposium on Evaluating Digital Cultural Resources (EDCR2016) which took place in Glasgow in December 2016. ScotDigiCH is coordinated by Information Studies at the University of Glasgow in collaboration with The Hunterian at the University of Glasgow, Glasgow Life Museums, the Moving Image Archive of the National Library of Scotland, and the Department of Computer and Information Sciences at the University of Strathclyde. Although the idea for this focused issue arose from the work of ScotDigiCH (and includes two articles initially presented at EDCR2016), we wanted to open it up further and invited submissions through an open Call for Papers from researchers and cultural heritage practitioners working in this area from around the world. Five of the over 50 articles submitted in response to the call were accepted and complete the issue, which comprises a total of seven articles.

We are very grateful to both the previous and current Editor-in-Chief of JOCCH (Roberto Scopigno from ISTI-CNR, Pisa, and Franco Niccolucci from VAST-LAB at PIN, University of Florence, respectively), and to the

(c) 2019 Copyright held by the owner/author(s).

1556-4673/2019/02-ART1e

https://doi.org/10.1145/3307313

ACM Journal on Computing and Cultural Heritage, Vol. 12, No. 1, Article 1e. Publication date: February 2019. 
Associate Editor and Information Director Karina Rodriguez-Echavarria from the University of Brighton, for welcoming our proposal and tirelessly supporting all work on the issue. We also thank the international pool of reviewers who honoured us with the time and effort they put into reviewing the papers and for contributing to their improvement.

The high number and diversity of submissions we received to our call is an indication of the growing importance of evaluation work in digital heritage. It is also a recognition that this special issue fills a gap by bringing to the fore considerations and factors that affect both digital cultural heritage practitioners and researchers. The quality of the articles we received was, in most cases, also very high. In our selection for this special issue, the focus was on articles that did not just present a specific digital system/game/platform but went beyond that to critically analyse in sufficient depth or breadth how this was used and valued by users; to address the issues that the evaluation raised; and/or to demonstrate that they were innovative in their methodological or theoretical approaches. Overall, we favoured articles that framed the cases studied in a broader context, so as to enable practitioners and researchers in the field to draw comparable or wider lessons.

The first article [Franzini et al.] compares users' needs and expectations from digital editions of texts with what is actually built and provided in these resources by the digital humanities community.

The second article [Gil and Economou] studies the online presentation of museums' collections information over a 10-year period (which is unusual for the digital cultural heritage field, where longitudinal studies are rare) and uses a constructivist theoretical framework to examine their philosophy of communication.

The third article [Damala et al.] proposes a flexible evaluation framework for the design and use of any kind of digital application in a museum setting, which includes the perspectives of not only museum visitors but also cultural heritage professionals and institutions, and it highlights the key areas that need to be carefully examined.

The fourth article [Pujol] evaluates how archaeological virtual environments convey to users the feeling of travelling to the past. It particularly examines the design elements that constitute a VR-mediated experience and the role of reconstructions and visual realism in achieving a feeling of Cultural Presence.

The fifth article [Raptis et al.] uses cognitive-style theory to evaluate how the design of cultural heritage serious games affects the players' visual and game-play behaviour and knowledge acquisition. The article examines these factors in relation to visual search tasks and illuminates the importance of considering users' cognitive characteristics in both the design and evaluation of digital cultural heritage applications.

The sixth article [Jones et al.] presents the qualitative evaluation of a location-aware mobile cultural heritage game designed to stimulate reflection about the city of Luxembourg's history; it further critically examines the role of evaluation (undertaken at a formative stage) in the app's design.

The seventh article [Galani and Kidd] analyses the evaluation of two mobile apps used outdoors and makes the case for reflexivity in digital heritage evaluation practices. The article reflects more broadly on the methodologi$\mathrm{cal}$ and ethical issues related to digital cultural evaluation and the limitations arising from the narrow application of task-oriented evaluation frameworks.

The collection of current trends and approaches in digital cultural heritage evaluation included in the issue clearly highlights the strong interdisciplinary nature of this area of evaluation work, which draws from a range of fields to inform both theoretical and methodological approaches. It also shows the need to develop diverse strategies depending on the stage of evaluation (front-end, formative, or summative), type of digital resource, targeted users, and organisational context. At the same time, some common challenges and issues emerged from across all the articles. These advocate the importance of close collaboration among researchers, practitioners, cultural heritage organisations, and their user groups. They also highlight the need for more reflection, robustness, honesty, and sharing of both positive and negative outcomes that evaluation might bring out.

ACM Journal on Computing and Cultural Heritage, Vol. 12, No. 1, Article 1e. Publication date: February 2019. 
Editorial Note for Special Issue on the Evaluation of Digital Cultural Resources-January 2019 • 1e:3

This dialogue and exchange of ideas, which started with the ScotDigiCH network and continues with this special issue, shows that an international community of practice and research is being built in this area with the capacity and desire to produce significant work that promises to lead to more fruitful experimentation in the future.

Maria Economou University of Glasgow

Ian Ruthven University of Strathclyde

Areti Galani Newcastle University

Milena Dobreva UCL Qatar

Marco de Niet Leiden University Libraries

Guest Editors 